\title{
Health Concerns of Textile Workers \& Associated Community
}

Tanweer UI Islam ( $\square$ tanweer@s3h.nust.edu.pk)

Assistant Professor, Department of Economics, National University of Sciences \& Technology, Sector H-12, Islamabad

\section{Research}

Keywords: Cotton dust, Power-looms, Respiratory diseases, Kasur

Posted Date: January 27th, 2021

DOI: https://doi.org/10.21203/rs.3.rs-152328/v1

License: () (1) This work is licensed under a Creative Commons Attribution 4.0 International License. Read Full License 


\section{Abstract}

Background: Workers in the textile industry risk developing various respiratory and pulmonary diseases due to exposure to cotton dust. The particles from the cotton lint are inhaled by the workers and results in the breathing problems including asthma, shortness of breath, cough and tightness in the chest. The poor health of labor contributes to the low productivity of the labor and in serious cases loss of jobs leading to the poverty.

Methods: This study explores the health profiles of the textile workers and associated community and contrast them against the health profile of the control group to factor out any confounding factors. The study is conducted on cotton industry in Kasur, Pakistan. We interviewed 207 workers, 226 people from associated community (living in vicinities of weaving units) and 188 people for control group (from areas far away from weaving units and people are not associated with weaving industry) based on stratified random sampling technique. We employed descriptive methods and logistic regression to explore the association between respiratory diseases and weaving workers.

Results: Overall, prevalence of postnasal drip, byssinosis, asthma, and chronic bronchitis were $47 \%, 35 \%, 20 \%$, and $10 \%$ respectively among the workers. These percentages are significantly higher than the control group. Among workers, $43 \% \& 21 \%$ feel difficulty in hearing against noisy background and at low volume respectively. Due to bad light arrangements at workstations, $21 \% \& 31 \%$ workers are suffering from myopia and hyperopia respectively. Proportions of the workers suffering from continuous headache, skin infection, depression, and low back pain are $28 \%, 29 \%, 27 \%$ and $44 \%$ respectively.

Conclusion: Better environment at workstations, use of protective gears and education are the factors which reduce the risk of associated diseases among workers.

\section{Introduction}

Many countries around the world heavily rely on their industries as they create employment opportunities, contribute to output production, and add to the country's wealth creation. Pakistan is a semi-industrialized economy with a strong agrarian background which provides a sturdy foundation for the textile industry to thrive. Pakistan's textile industry has become the country's mainstay contributing approximately $8.5 \%$ to the overall GDP whilst generating employment opportunities to 38 percent of the manufacturing workforce and 45 percent of the overall workforce which is a compelling number considering that Pakistan is a labor abundant country. It is the 8th largest exporter of textile products in Asia and contributes $57 \%$ to the country's export revenues.

In Pakistan, about 15 million out of the total 49 million unskilled work force is employed in the textile industry, it is imperative to shed light on the working conditions these workers must endure during their tenure in this industry. There are several health and safety issues that workers in a textile industry must face irrespective of the unit they are working in it. The vast availability of labor, low health and safety standards and negligible implementation of laws on behalf of the government are putting the health of labor working in the industry in grave danger.

The weaving unit involves the process of threading or interlacing together different yarns to make cloth or fabric. There are certain health hazards workers might be exposed to in weaving units, be it integrated or independent weaving units or power loom units. The particles from the cotton lint are inhaled by the workers and results in the breathing problems including asthma, shortness of breath, cough, and tightness in the chest. The poor health of labor contributes to the low productivity of the labor and in serious cases loss of jobs leading to the poverty. The association between the existence of respiratory illnesses among the industrial workers from the cotton dust is well recognized in literature (see e.g. Roy et. al, 2019, Mahmood, 2019, Ali et. al, 2018, Mastrangelo, Fedeli, Fadda, Milan, \& Lange, 2002; Memon et al., 2008; Farooque et al., 2008; Ayesha, et al., 2009; Nafees et. al., 2013 \& Paudyal et. al., 2011).

Due to extended exposure to cotton dust, workers in the cotton processing industries face risk of developing obstructive respiratory conditions (Mberikunashe et. al., 2010). The affected workers of the factory further transform the diseases to the members of their family that widen the effects to the overall community. These effects caused by exposure to cotton dust could be short term and long term chronically damaging the overall health publicly (Xie et al., 2011). They are also prone to developing musculoskeletal disorders like carpal tunnel syndrome, forearm tendinitis, bicipital tendinitis, lower back pain, epicondylitis, neck pain, shoulder pain, and osteoarthritis due to bad postures for long hours and lifting heavy weights.

Workers might also develop hearing problems due to some weaving machines emitting noises greater than $90 \mathrm{dBs}$. Continued exposure to noise may have damaging consequences for people who experience it for long stretches of time. High noise causes speech interference and hearing loss (Ashraf et. al., 2009). Yildirim et. al., (2007) investigated that hearing threshold of the textile workers changes significantly as compared to normal human beings and the noise causes oxidative stress among the textile workers. In the long term, the effects are not only limited to a sensory deficit but are rather influential on the psychological as well as economic aspect of a worker's life. Moreover, cotton dust can cause various pulmonary disorders and may even cause skin irritation (Ayesha et al., 2009 and Tahir et al., 2012).

The scarce literature on occupational health in weaving industry of Pakistan highlights the associated diseases among the workers of weaving industry without comparing with the control group or without controlling for the confounding factors. There is hardly any study available which studies the impact of ambient particulate matter (cotton dust) on the health of associated community. This study is aiming to bridge this gap in literature by (i) comparing the treatment group (weaving industry workers) with the control group and (ii) studying the impact on the associated community. This study mainly focuses on the health hazards that workers employed in the textile industry in District Kasur are exposed to. District Kasur was formed in 1976 and is located at about 55 kilometers towards South of Lahore with a population of 3,454,996 (Bureau of Statistics, 2017). Tanneries and textiles are major industries in the district. Overall, the textile sector in district Kasur comprises of 7756 looms, 46,916 rotors and 2,036,489 spindles (Pre-Investment Study- District Kasur, 2012).

\section{Methods}


We conducted a cross-sectional study in dozens of small weaving units located in East, West, and South-East of Kasur, Punjab. We randomly selected 7, 7 \& 6 units from East, South-East and West strata respectively. Overall, we interviewed 207 workers, 226 people from associated community and 188 people for the control group. Control group comprises of those who neither work in weaving industry nor live near to it, associated group consists of those individuals who live about the industry and workers are those who are working in the weaving industry of Kasur. All the workers present on duty during our visit were interviewed. Well-trained investigators filled out the structured questionnaire because most of the respondents were illiterate. We briefed all the respondents about the purpose of the study and obtained their consent. Majority of our respondents were male workers (90.0\%) with average age of 42 years and standard deviation of 13 years.

We employed descriptive methods and logistic regression to explore the association between respiratory diseases and weaving workers. Logistic regression analysis is used to study the impact of education, work experience and working environment on the prevalence rate of different respiratory diseases. Factor Analysis technique is used to construct an index of work environment using questions asked to workers relating to work environment and their satisfaction in this regard.

\section{Results}

\section{DESCRIPTIVE ANALYSIS}

Table 1 summarizes the descriptive statistics of the household indicators of the three groups. Age and education are two elements that influence human behavior towards occupational health and safety either directly or indirectly. The economic condition of an individual may be gauged through their reported monthly income and their health status can be assessed through the health expenditures. The average age of respondents from the control, associated and worker's groups were 39, 41 and 42 years, respectively. Most of the individuals in the samples of the three groups were male. The average educational level for control and associated groups is primary and below primary for workers. Average number of children are 2 in all groups and adults are 6 for control and associated groups and 4 for workers group. To compare the average monthly income levels of the groups, we apply ANOVA test which rejects the hypothesis of equal monthly income across the groups ( $p$-value $=0.0002)$. Workers visit district hospital Kasur more frequently than other

Table 1

Descriptive Statistics: Household Indicators

\begin{tabular}{|c|c|c|c|c|c|c|c|c|c|c|c|c|}
\hline \multirow[t]{2}{*}{ Variables/Groups } & \multicolumn{4}{|c|}{ Control Group $(n=188)$} & \multicolumn{4}{|c|}{ Associated Group $(n=226)$} & \multicolumn{4}{|c|}{ Workers $(n=207)$} \\
\hline & Mean & Std. Dev. & Min & Max & Mean & Std. Dev. & Min & Max & Mean & Std. Dev. & Min & Max \\
\hline Age & 39 & 14.96 & 15 & 80 & 41 & 15.29 & 14 & 80 & 42 & 13.12 & 14 & 85 \\
\hline Education & 5 & 5.10 & 0 & 16 & 6 & 5.68 & 0 & 16 & 2 & 3.67 & 0 & 14 \\
\hline Sex (Male \%) & 0.86 &.. &.. & .. & 0.87 & .. &.. & .. & 0.90 & .. &.. &.. \\
\hline Adults & 6.19 & 3.70 & 2 & 22 & 6.14 & 3.57 & 2 & 35 & 4.15 & 2.48 & 2 & 12 \\
\hline Children & 2.04 & 2.13 & 0 & 12 & 1.88 & 2.04 & 0 & 8 & 2.07 & 2.09 & 0 & 9 \\
\hline Monthly Income & 18290 & 17810 & 0 & 200000 & 16948 & 12597 & 0 & 55000 & 13165 & 4459 & 2000 & 40000 \\
\hline Health Expenditure ${ }^{a}$ & 2155 & 2586 & 0 & 20000 & 1892 & 1641 & 0 & 12000 & 1273 & 1574 & 0 & 14000 \\
\hline
\end{tabular}

Control group comprises of those who neither work in weaving industry nor live near to it, associated group consists of those individuals who live about the industry and workers are those who are working in the weaving industry of Kasur.

Table 2

Descriptive Statistics: Working Environment

\begin{tabular}{|llllll|}
\hline Variable & Obs. & Mean & Std. Dev. & Min & Max \\
\hline Ventilation & 207 & 0.72 & 0.45 & 0 & 1 \\
\hline Ventilation Satisfaction & 207 & 0.71 & 0.45 & 0 & 1 \\
\hline Light Satisfaction & 207 & 0.78 & 0.42 & 0 & 1 \\
\hline Washroom Availability & 207 & 0.88 & 0.33 & 0 & 1 \\
\hline Washroom Cleanliness Satisfaction & 207 & 0.62 & 0.49 & 0 & 1 \\
\hline Availability of First Aid & 207 & $\mathbf{0 . 1 1}$ & 0.31 & 0 & 1 \\
\hline Head \& Nose Cover & 207 & $\mathbf{0 . 0 5}$ & 0.22 & 0 & 1 \\
\hline Use of Protective Gears & 207 & $\mathbf{0 . 0 2}$ & 0.15 & 0 & 1 \\
\hline
\end{tabular}


Table 3

Descriptive Statistics: Group-wise Diseases \& Smoking Habits

\begin{tabular}{|c|c|c|c|c|c|c|c|c|c|}
\hline \multirow[t]{2}{*}{ Variable } & \multicolumn{3}{|c|}{ Workers } & \multicolumn{3}{|c|}{ Control } & \multicolumn{3}{|c|}{ Associated } \\
\hline & Obs. & Mean & Std. Dev. & Obs. & Mean & Std. Dev. & Obs. & Mean & Std. Dev. \\
\hline Smoking & 207 & 0.37 & 0.48 & 188 & 0.22 & 0.41 & 226 & 0.23 & 0.42 \\
\hline Years of Smoking & 207 & 7.49 & 12.74 & 188 & 3.03 & 7.96 & 226 & 3.81 & 9.26 \\
\hline Cigarettes smoked per day & 206 & 3.82 & 6.58 & 187 & 2.18 & 5.42 & 226 & 2.20 & 5.08 \\
\hline Postnasal Drip & 207 & 0.47 & 0.50 & 188 & 0.10 & 0.30 & 226 & 0.06 & 0.24 \\
\hline Byssinosis & 207 & 0.35 & 0.48 & 188 & 0.18 & 0.39 & 226 & 0.12 & 0.32 \\
\hline Asthma & 207 & 0.20 & 0.40 & 188 & 0.12 & 0.33 & 226 & 0.14 & 0.34 \\
\hline Chronic Bronchitis & 207 & 0.10 & 0.30 & 188 & 0.06 & 0.24 & 226 & 0.05 & 0.22 \\
\hline Myopia & 207 & 0.21 & 0.41 & 188 & 0.24 & 0.43 & 226 & 0.32 & 0.47 \\
\hline Hyperopia & 207 & 0.31 & 0.46 & 188 & 0.18 & 0.38 & 226 & 0.34 & 0.47 \\
\hline Audibility Against Noisy Background & 207 & 0.43 & 0.50 & 188 & 0.10 & 0.30 & 226 & 0.10 & 0.30 \\
\hline Audibility Issue at Low Volume & 207 & 0.21 & 0.41 & 188 & 0.11 & 0.31 & 226 & 0.08 & 0.28 \\
\hline Ear Sufferings & 207 & 0.26 & 0.44 & 188 & 0.03 & 0.18 & 226 & 0.01 & 0.11 \\
\hline Continuous Headache & 207 & 0.28 & 0.45 & 188 & 0.06 & 0.25 & 226 & 0.10 & 0.30 \\
\hline Skin Infections & 207 & 0.29 & 0.45 & 188 & 0.07 & 0.26 & 226 & 0.06 & 0.24 \\
\hline Depression & 207 & 0.27 & 0.45 & 188 & 0.13 & 0.34 & 226 & 0.07 & 0.25 \\
\hline Low Back Pain & 207 & 0.44 & 0.50 & 188 & 0.31 & 0.47 & 226 & 0.25 & 0.43 \\
\hline
\end{tabular}

groups for free treatment and medicine. Additionally, on an average, all three groups spend equal proportion of their income for health services ( $p$-value = 0.2864). This indicates that the textile workers relatively face more burden of diseases as compared to associated community and control group.

Workers were inquired about the availability of ventilation, adequate lighting, washrooms, first aid and protective gears and they were to report their satisfaction with the facilities provided (Table 2). Majority of the weaving units provide ventilation and toilet facility to workers however only 62 percent are satisfied with the hygiene of washrooms. First aid facility is not available to 89 percent workers at their workstations and 5 percent cover their head \& nose on duty. However, an overwhelmingly low percentage $(2 \%)$ reported actual usage of the protective gears. These statistics further reiterate the fact that there is a need to promote provision of protective gears to the workers and create awareness amongst the workers to safeguard themselves against a plethora of occupational health hazards. Table 3 highlights the prevalence of diseases and smoking habits across the three groups of individuals. Smoking was seen to be predominant amongst the weavers (37\%) with years of smoking averaging at 7.49 and 4 cigarettes being smoked per day on average. In comparison, the prevalence of smoking is lower in the individuals of the control group and associated communities i.e. $22 \%$ and $23 \%$ respectively.

Table 3 indicates that $47 \%$ workers complain of postnasal drip which may be described as a feeling of mucus secretions moving up and down the back column of the throat that causes a constant need to cough to clear the throat. The incidence of postnasal drip was much lower amongst individuals of associated community (6\%) and amongst the control group (10\%). Among 207 workers, the occurrence of byssinosis was found to be 35 percent whereas it was 12 and 18 percent in associated community and control group respectively. This is primarily due to the fact that byssinosis, in itself, is an occupational lung disease that cotton industry workers are most prone to due to presence of cotton dust in their surrounding environments (Anyfantis et. al, 2017). More importantly, inadequate ventilation in the weaving units adds to its causation. Similarly, asthma and chronic bronchitis was found to be dominant amongst the workers $(20 \% \& 10 \%)$ as opposed to individuals in the control $(12 \% \& 6 \%)$ and associated community $(14 \% \& 5 \%)$. Weavers are on an advantage to other groups in terms of myopia (nearsightedness) and hyperopia (far sightedness) respectively. This could be an indication that the workers were indeed satisfied with the lighting conditions as mentioned earlier. Audibility issues and ear sufferings were overwhelmingly dominant in the weavers. A great majority complained of audibility against noisy background (43\%); $21 \%$ complained of audibility issues at low volume and $26 \%$ of miscellaneous ear sufferings. In comparison, the control and associated communities were found to have lesser hearing and ear problems. Again, the ear problems are aggravated amongst the weavers due to loud machines and a lack of provision of protecting equipment like earmuffs etc. Moreover, amongst workers $28 \%$ suffered from continuous headaches which may be a result of exposure of continuous industry noise or work-related stress. In comparison, the incidence of headaches was lower in the control group and associated communities. Prevalence of skin infections amongst workers was four time higher (29\%) as compared to control group (7.0\%). This could also be attributed to exposure to cotton dust. Furthermore, $27 \%$ of the worker were reportedly suffering from depression as well. A great majority (44\%) suffered from lower back pains which could be due to lifting heavy rollers and continuously standing on power-looms for an extended period during weaving. 
Table 4

Descriptive Statistics: Other Diseases

\begin{tabular}{|llll|}
\hline Diseases & Freq. & Percent & Cum. \\
\hline COPD & 48 & 43.64 & 43.64 \\
\hline Lungs Cancer & 3 & 2.73 & 46.36 \\
allergic rhinitis & 1 & 0.91 & 47.27 \\
\hline fungal infection & 4 & 3.64 & 50.91 \\
\hline lung abscess & 1 & 0.91 & 51.82 \\
\hline Sinusitis & 53 & 48.18 & 100.00 \\
\hline
\end{tabular}

Table 4 presents the descriptive statistics of other diseases that the workers either suffered from or diseases that were deduced from the color of mucus they reported when the questionnaires were administered. Out of 110 workers, $43.6 \%$ suffered from chronic obstructive pulmonary disorder (COPD), $48.1 \%$ from sinusitis, $3.64 \%$ from fungal infections, $2.73 \%$ from lung cancer and $0.91 \%$ from lung abscess as well as allergic rhinitis. Our findings related to COPD are in line with Mahmood, (2019).

We called in the Chi-square statistic for testing the hypothesis of no association between the groups and various diseases. The null hypothesis of no association is rejected for all diseases except for asthma and chronic bronchitis at $5 \%$ level of significance (Table 5). Thus, we may conclude that these diseases are linked with working in the weaving industry. At $10 \%$ level of significance, all diseases are associated with working in the weaving industry.

In short, the weaving industry workers in Kasur are more prone to postnasal drip, byssinosis, asthma, chronic bronchitis, myopia, hyperopia, audibility against noisy background, audibility issue at low volume, ear sufferings, headache, skin infection, depression and lower back pain than the comparison groupsassociated community and control group due to the septic environment at work and smoking habits. Our results not only corroborate with the existing literature (Ali et al., 2018, Nafees et al., 2013, Memon et al., 2008; Farooque et al., 2008; Ayesha, et al., 2009) but also strengthen the findings of literature that cotton dust is responsible for the associated diseases in textile industry.

Table 5

Chi2-Test Results

\begin{tabular}{|lll|}
\hline \multicolumn{3}{|c}{ Chi2-Test Results } \\
\hline Variable & Chi2 & P-value \\
\hline Smoking & 15.14 & 0.0010 \\
\hline Postnasal & 129.10 & 0.0000 \\
\hline Byssinosis & 38.02 & 0.0000 \\
\hline Asthma & 5.05 & 0.0800 \\
\hline Chronic Bronchitis & 5.15 & 0.0760 \\
\hline Myopia & 7.81 & 0.0200 \\
\hline Hyperopia & 14.64 & 0.0010 \\
\hline Audibility Against Noisy Background & 91.61 & 0.0000 \\
\hline Audibility Issue at Low Volume & 15.96 & 0.0000 \\
\hline Ear Sufferings & 84.69 & 0.0000 \\
\hline Headache & 43.81 & 0.0000 \\
\hline Skin Infection & 54.27 & 0.0000 \\
\hline Depression & 35.42 & 0.0000 \\
\hline Low Back Pain & 19.26 & 0.0000 \\
\hline Family Respiratory History & 22.15 & 0.0000 \\
\hline
\end{tabular}


Table 6

Logistic Regression Results

\begin{tabular}{|c|c|c|c|c|c|c|c|c|c|c|c|}
\hline VAR & Postnasal & Byssinosis & Asthma & $\begin{array}{l}\text { Chronic } \\
\text { Bronchitis }\end{array}$ & Myopia & Hyperopia & $\begin{array}{l}\text { Ear } \\
\text { Sufferings }\end{array}$ & Headache & $\begin{array}{l}\text { Skin } \\
\text { Infections }\end{array}$ & Depression & $\begin{array}{l}\text { Low } \\
\text { back } \\
\text { pain }\end{array}$ \\
\hline \multirow[t]{2}{*}{ Edu } & $-0.12^{\star \star \star}$ & -0.06 & -0.04 & -0.03 & 0.06 & 0.06 & -0.07 & 0.00 & -0.06 & -0.04 & $-0.078 *$ \\
\hline & $(0.05)$ & $(0.05)$ & $(0.05)$ & $(0.07)$ & $(0.05)$ & $(0.04)$ & $(0.05)$ & $(0.04)$ & $(0.05)$ & $(0.05)$ & $(0.04)$ \\
\hline \multirow{2}{*}{$\begin{array}{l}\text { Work } \\
\text { Exp. }\end{array}$} & $0.06^{\star \star *}$ & $0.06^{\star \star *}$ & $0.05^{\star \star \star}$ & $0.05^{\star \star \star}$ & $0.024^{*}$ & $0.06 * * \star$ & $0.03^{\star *}$ & 0.01 & $0.027 * *$ & $0.033^{\star \star *}$ & $0.036^{\star * *}$ \\
\hline & $(0.01)$ & $(0.01)$ & $(0.02)$ & $(0.02)$ & $(0.01)$ & $(0.01)$ & $(0.01)$ & $(0.01)$ & $(0.01)$ & $(0.01)$ & $(0.01)$ \\
\hline \multirow{2}{*}{$\begin{array}{l}\text { Env. } \\
\text { Index }\end{array}$} & $-0.3^{* \star \star}$ & -0.15 & 0.16 & -0.05 & -0.02 & -0.15 & -0.17 & -0.28 ** & -0.07 & -0.17 & 0.07 \\
\hline & $(0.12)$ & $(0.12)$ & $(0.15)$ & $(0.17)$ & $(0.13)$ & $(0.12)$ & $(0.12)$ & $(0.11)$ & $(0.12)$ & $(0.12)$ & $(0.11)$ \\
\hline \multirow[t]{2}{*}{ Constant } & -0.37 & 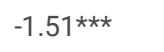 & $-3.1 * \star \star$ & 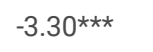 & $-2.0 * \star \star$ & $-2.1 * \star \star$ & $-1.133^{\star \star}$ & -0.51 & $-1.252^{\star \star}$ & $-1.275^{\star \star}$ & $-1.059 * *$ \\
\hline & $(0.48)$ & $(0.50)$ & $(0.66)$ & $(0.80)$ & $(0.57)$ & $(0.53)$ & $(0.50)$ & $(0.47)$ & $(0.49)$ & $(0.50)$ & $(0.46)$ \\
\hline$N$ & 207 & 207 & 207 & 207 & 207 & 207 & 207 & 207 & 207 & 207 & 207 \\
\hline \multicolumn{12}{|c|}{ Standard errors in parentheses } \\
\hline$\star * * p<0.0$ & $p<0.05$, & $<0.1$ & & & & & & & & & \\
\hline
\end{tabular}

\section{REGRESSION ANALYSIS}

Table 6 summarizes the logistic regression results highlighting the relationship between the associated diseases and work experience, educational level of the workers \& the index for work environment. The index is constructed by using the factor analysis technique to the questions asked to worker relating to work environment and their satisfaction in this regard.

The results indicate that the educated workers are less likely to caught by postnasal drip and low back pain as compared to their peer group with low or no education. The cotton dust exposure leads to postnasal drip problem and lifting heavy cotton sacks and rollers causes low back pain among the workers. Highly significant relationship is found between work experience and all associated diseases among the weaving workers in Kasur. More work experience means more exposure to cotton dust and more prone to associated diseases like postnasal drip, byssinosis, asthma, chronic bronchitis, myopia, hyperopia, audibility against noisy background, audibility issue at low volume, ear sufferings, skin infection, depression and lower back pain.

Other than cotton dust, the light and ventilation arrangements and other hygienic conditions (based on the worker's perception) are merged into an index, Env. Index, is indicating that more satisfied the worker is with the aforementioned arrangements less likely to suffer from associated diseases. Where the owner of the weaving units provides better light and ventilation arrangements, workers are less likely to suffer from postnasal drip and headache. Our results strengthen the findings in Mahmood, (2019).

\section{Discussion}

This study explores the health profiles of the textile workers and associated community and contrast them against the health profiles of the control group. This allows us to factor out any confounding factors while establishing the association between the diseases and work environment. We interviewed 207 workers, 226 people from associated community (living in vicinities of weaving units) and 188 people for control group (from areas far away from weaving units and people are not associated with weaving industry) based on stratified random sampling technique. We employed descriptive methods (t- \& Chisquare tests) and logistic regression to explore the association between respiratory diseases and weaving workers.

Average educational level for control and associated groups is primary and below primary for workers. Workers in the weaving industry of Kasur are earning less than the control group ( $p$-value $=0.0002$ ) and the official minimum wage, PKR 17500 but facing relatively more burden of disease. Due to low education and awareness only 2 percent use proper protective gears leading to high incidence of associated diseases. Furthermore, smoking was predominant amongst the weaving workers (37\%). On an average, a worker smokes 4 cigarettes per day with 7.5 years of smoking history. This reiterate the fact that there is a dire need to promote provision of protective gears to workers and to educate them.

Among 207 workers, the occurrence of postnasal drip, byssinosis, asthma, audibility against noisy background, continuous headache, depression and low back pain is significantly higher than the control group. Chi-square test rejects the null hypothesis of no association between the three groups and diseases (Table 5). These findings corroborate with the existing literature (Ali et al., 2018, Nafees et al., 2013, Memon et al., 2008; Farooque et al., 2008; Ayesha, et al., 2009). Cotton industry workers are more prone to occupational lungs diseases due to the presence of cotton dust in their surrounding environment (Anyfantis et al., 2017). Continuous exposure to noisy background leads to ear sufferings and frustration among the workers. During interviews, many works reveal that they want to quit the job but they are unable to find the alternate due to low educational level which frustrate them. However, mostly are eager to invest in their children education to provide them better job opportunities. 
Logistic regression is used to explore the linkages between the work experience, educational level of the workers \& the index for work environment and the associated diseases. Regression results (Table 6) indicate that the educated workers are less likely to caught by postnasal drip and low back pain as compared to their peer group with low or no education. Figure 1 clearly indicates that the prevalence of postnasal drip and low back pain is less among workers with better educational level as they avoid lifting heavy rollers and take local remedies against postnasal drip such as frequently drinking tea to clear their throat and eating gurr (raw form of sugar). Highly significant relationship is found between work experience and all associated diseases among the weaving workers in Kasur. More work experience means more exposure to cotton dust and more prone to associated diseases. Workers were asked questions relating to work environment and their satisfaction in this regard and an index is constructed based on their perception in this regard by using the factor analysis technique. Where the owner of the weaving units provides better light and ventilation arrangements, workers are less likely to suffer from postnasal drip and headache. Our results strengthen the findings in Mahmood, (2019).

\section{Conclusion}

Highly septic infrastructure in the local weaving industry is the root cause of various diseases among the workers. Due to elongated exposure to cotton dust, workers in the cotton processing industries face risk of developing obstructive respiratory conditions.

We interviewed 207 workers, 226 people from associated community (living nearby the weaving unit) and 188 people for control group (from areas far away from weaving units and people are not associated with weaving industry) and contrasted the results to control for confounding factors. Cotton dust, smoking, time spent in cotton industry, working environment, low income and lack of financial support for medication, non-availability of protective gears and low level of education are the causes of the high incidence of associated diseases among the workers of small-scale weaving industry of Kasur. Postnasal drip, byssinosis, asthma, chronic bronchitis, continuous headache, depression, low back pain and skin infection were the noticeable health consequence of cotton dust in weaving industry. We recommend training courses both for the workers and the managers of these small units to create awareness and provision of protective gears and first aid.

\section{Declarations}

- The Ethics Committee, School of Social Sciences \& Humanities ( $\mathrm{S} 3 \mathrm{H})$ kindly granted the approval of the study. Workers, associated community, and the people in control group were briefed about the purpose of the study and the consent for participation was obtained from them.

- Consent for publication is granted by all stakeholders.

- Supporting data are available from the corresponding author upon request.

- Conflict of Interest: The author declares that he has no conflict of interest.

- Funding: This research is funded by Higher Education Commission of Pakistan under the Thematic Research Grant Program (TRGP)-2017-18 (Award No. 6(05)/Acad/SS\&H/HEC/2018/77).

- Registration No. NA

- Animal Studies: NA

\section{Author's Contribution:}

Islam, T. devised the project, main conceptual ideas and proof outline. Islam, T. worked out almost all of the technical details including construction and validation of the questionnaire, data collection plan, data cleaning, estimation of results, and manuscript write up.

\section{Acknowledgement:}

This paper and the research behind this would not have been possible without the support of Higher Education Commission, Pakistan. Author would like to express his gratitude to Profs. Asma Hyder and Anwar Shah for their valuable comments on the initial draft of the manuscript.

\section{Conflicts of Interest Statement:}

The author certify that he has NO affiliations with or involvement in any organization or entity with any financial interest, or non-financial interest in the subject matter or materials discussed in this manuscript.

\section{References}

1. Ali, N. A., Nafees, A. A., Fatmi, Z., \& Azam, S. I. (2018). Dose-response of cotton dust exposure with lung function among textile workers: MultiTex Study in Karachi, Pakistan. The international journal of occupational and environmental medicine, 9(3), 120.

2. Anyfantis, I. D., Rachiotis, G., Hadjichristodoulou, C., \& Gourgoulianis, K. I. (2017). Respiratory symptoms and lung function among Greek cotton industry workers: a cross-sectional study. The international journal of occupational and environmental medicine, 8(1), 32.

3. Ashraf, H. D., Younus, M. A., Kumar, P., Siddiqui, M. T., Ali, S. S., \& Siddiqui, M. I. (2009). Students' Corner-Frequency of hearing loss among textile industry workers of weaving unit in Karachi, Pakistan. The Journal of the Pakistan Medical Association, 59(8), 575.

4. Ayesha, A., Mann, A. A., \& Anjum, M. A. (2009). Health concerns among workers in weaving industry: A case study of tehsil Faisalabad, Pakistan. Journal of Agriculture and Social Sciences, 5(3), 106-108. 
5. Farooque, M. I., Khan, B., Aziz, F., Moosa, M., Raheel, M., Kumar, S., \& Mansuri, F. A. (2008). Students' Corner-Byssinosis: As seen in cotton spinning mill workers of Karachi. The Journal of the Pakistan Medical Association, 58(2), 95.

6. Mahmood, A. (2019). Effects of Nuisance Dust (Total) on Health of workers of Textile Sector in Punjab (Pakistan)(Doctoral dissertation, University of the Punjab, Lahore).

7. Mastrangelo, G., Fedeli, U., Fadda, E., Milan, G., \& Lange, J. H. (2002). Epidemiologic evidence of cancer risk in textile industry workers: a review and update. Toxicology and industrial health, 18(4), 171-181.

8. Memon, I., Panhwar, A., Rohra, D. K., Azam, S. I., \& Khan, N. (2008). Prevalence of byssinosis in spinning and textile workers of Karachi, Pakistan. Archives of environmental \& occupational health, 63(3), 137-142.

9. Mberikunashe, J., Banda, S., Chadambuka, A., Gombe, N. T., Shambira, G., Tshimanga, M., \& Matchaba-Hove, R. (2010). Prevalence and risk factors for obstructive respiratory conditions among textile industry workers in Zimbabwe, 2006. Pan African Medical Journal, 6(1).

10. Nafees, A. A., De Matteis, S., Kadir, M. M., Burney, P., Coggon, D., Semple, S., \& Cullinan, P. (2019). MultiTex RCT-a multifaceted intervention package for protection against cotton dust exposure among textile workers-a cluster randomized controlled trial in Pakistan: study protocol. Trials, $20(1)$, 1-10.

11. Nafees, A. A., Fatmi, Z., Kadir, M. M., \& Sathiakumar, N. (2013). Pattern and predictors for respiratory illnesses and symptoms and lung function among textile workers in Karachi, Pakistan. Occup Environ Med, 70(2), 99-107.

12. Paudyal, P., Semple, S., \& Ayres, J. (2011). Respiratory symptoms and lung function in relation to cotton dust and endotoxin exposure in textile workers in Nepal. Occup Environ Med, 68(Suppl 1), A65-A65.

13. Roy, P. P., Manjula, S. R., Siddhartha, K., \& Sudhakar, K. (2019). Comparative study of pulmonary function in human beings exposed to cotton fiber and non-exposed human beings. Indian Journal of Clinical Anatomy and Physiology, 6(1), 98-102.

14. Tahir, M. W., Mumtaz, M. W., Tauseef, S., Sajjad, M., Nazeer, A., Farheen, N., \& Iqbal, M. (2012). Monitoring of cotton dust and health risk assessment in small-scale weaving industry. Environmental monitoring and assessment, 184(8), 4879-4888.

15. Yildirim, I., Kilinc, M., Okur, E., Tolun, F. I., Kilic, M. A., Kurutas, E. B., \& Ekerbicer, H. C. (2007). The effects of noise on hearing and oxidative stress in textile workers. Industrial health, 45(6), 743-749.

16. Xie, P., Liu, X., Liu, Z., Li, T., Zhong, L., \& Xiang, Y. (2011). Human health impact of exposure to airborne particulate matter in Pearl River Delta, China. Water, Air, \& Soil Pollution, 215(1-4), 349-363.

\section{Figures}
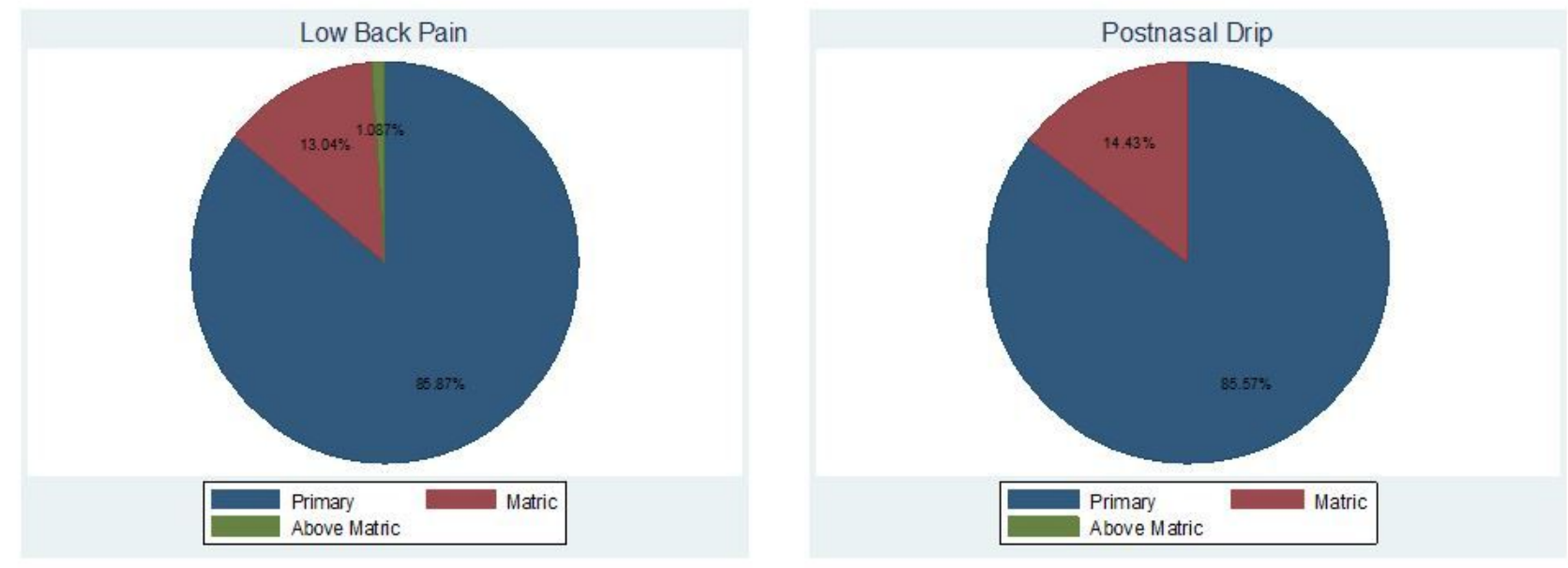

Figure 1

Educational level and Prevalence of Postnasal \& Low Back Pain 